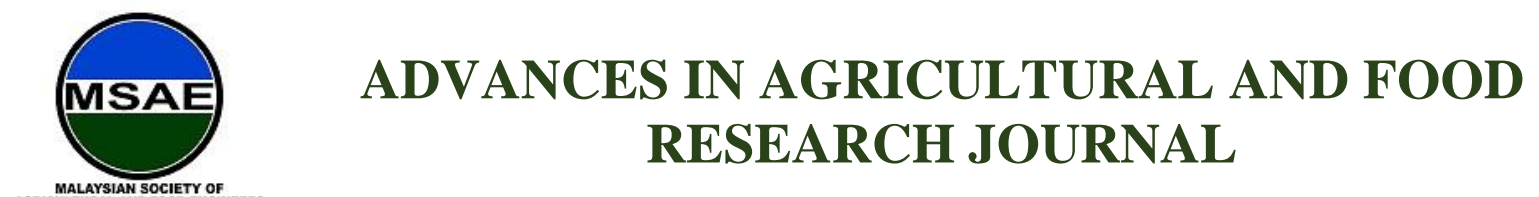

Original Research Article

\title{
Design and Development of an Indoor Testing Facility for Downwash and Spray Distribution Evaluations of Agricultural UAV
}

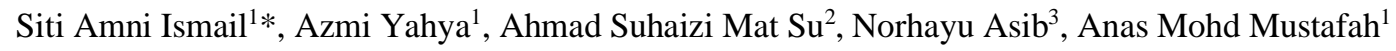

${ }^{1}$ Department of Biological and Agricultural Engineering, Universiti Putra Malaysia, Serdang, 43400, Malaysia, azmiy@upm.edu.my, anas_mustafah@upm.edu.my.

${ }^{2}$ Department of Agriculture Technology, Universiti Putra Malaysia, Serdang, 43400, Malaysia, asuhaizi@upm.edu.my.

${ }^{3}$ Department of Plant Protection, Universiti Putra Malaysia, Serdang, 43400, Malaysia, norhayuasib@upm.edu.my.

*Corresponding author: Siti Amni Ismail, Department of Biological and Agricultural Engineering, Universiti Putra Malaysia, Serdang, 43400, Malaysia; sitiamni@gmail.com

\begin{abstract}
The usage of UAV as a pesticide application technology is becoming a common practice in Southeast Asia, with a substantial proportion of agricultural areas currently being treated using this method. To date, more than 169 different UAV designs and configurations have been developed to meet such demand. Each UAV design and configuration have its own unique aerodynamic effects that may have an impact on the resulted spray droplet characteristics and distributions. Therefore, it is crucial to determine both the downwash airflow and spray patterns, and also the effective spraying application parameters for the UAV. This research outlines the development of an indoor test facility and its standardised test procedure for evaluating the downwash airflow and spraying performance of any UAV model used in agricultural applications. The test facility was designed to imitate the UAV in the actual field spraying operation. The developed test facility is $23 \mathrm{~m}$ long and has been designed to mount the UAV at up to $100 \mathrm{~kg}$, at three spray heights $(1.5 \mathrm{~m}, 2.5 \mathrm{~m}$ and $3.5 \mathrm{~m})$ and operating at a maximum travel speed of $10 \mathrm{~m} / \mathrm{s}$. The $6 \times 6 \mathrm{~m}$ sampling platform structure for pressure sensors and water-sensitive paper was built under the rail support structure to measure and collect data for the spraying distributions and downwash pressure profiles. With an indoor UAV test facility, recurring experiments based on the same standard protocols could be made available, prospecting improved UAV spraying efficiency and proper recommendations on UAV flying requirements to achieve an efficient agricultural chemical spraying operation.
\end{abstract}

Keywords: aerial spraying; unmanned aerial vehicle; agricultural chemical spraying; test rig; downwash air flow profile; spray distribution. 
Received: $18^{\text {th }}$ November 2020

Accepted: $18^{\text {th }}$ December 2020

Available Online: $25^{\text {th }}$ December 2020
Citation: Ismail SA, Yahya A, Mat Su AS, et al. Design and development of an indoor testing facility for downwash and spray distribution evaluations of agricultural UAV. Adv Agri Food Res J 2020; 1(2): a0000157. https://doi.org/10.36877/aafrj.a0000157

\section{Introduction}

Unmanned Aerial Vehicle (UAV) is a technology that has revolutionized modern agriculture and is expected to become one of the technologies of the future (Huang et al., 2013). UAV has been involved in a wide range of agricultural production tasks, such as: (i) acquiring data from a variety of sensors for soil nutrients and crop health status; (ii) as a mechanical applicator for broadcasting seeds, spreading granular fertilizers, and spraying of herbicide and pesticide chemicals (Puig et al., 2018). In China alone, almost 95\% of Chinese agricultural aviation technology have been used in aerial plant protection operations, while the other 5\% have been used in the acquisition of agricultural information (He et al., 2017).

UAV as a pesticide application technology has become a common practice in Southeast Asia, with a very significant proportion of agricultural areas currently being treated using this method. In China, due to the high demand, there are more than 200 UAV manufacturers that produce more than 169 different UAV designs and configurations for pesticide application (He et al., 2017). With the advantages of the UAV, it is expected to increase field capacity (ha/hr), replace human labor, reduce health problems due to pesticide exposure, high site-specific accuracy and also good for vector control in areas that are hardly accessible by man (Faiçal et al., 2017; Huang et al., 2009; Mievel et al., 2016; Morley et al., 2016). Past research by Giles and Billing (2014) indicated that, depending on the applied spraying method, flight pattern, and spray width, field capacities were able to reach between 2.0 and $4.5 \mathrm{ha} / \mathrm{h}$, while the application rate was between 14.0 and $39.0 \mathrm{~L} / \mathrm{ha}$.

In general, although the utilization of UAV has many advantages and most likely solved many problems in the field, more attention should be paid specifically to the use of UAV in spraying operation. Basically, the UAV needs to meet the prime objective of pesticide application where the spray droplets must be uniformly distributed on the target surface with minimal losses due to drift, run-off or evaporation. However, based on the previous studies, Wang et al. (2017) that analyzed the performance of four UAVs typically used for pesticide operations in China stated that the pesticide applications of UAV were on a low precision and unsatisfactory. The deposition pattern and liquid spraying distribution were found to be not uniform both in lateral and longitudinal directions. Similar results were reported by Qin et al. (2016) in paddy cultivation and Zhang et al. (2016) in citrus growing. The size of droplets produced and the deposition of droplets during spraying is influenced by few factors namely environmental conditions (i.e. wind speed, humidity), spray chemical, leaf properties, and the whole spray system (i.e. spray nozzle, operating pressure) used or set 
during the operation (Hofman \& Solseng, 2017; Pscheidt, 2012). During spraying application using UAV, the produced spray droplets produced were found to be affected by the rotor airflow (downwash) which severely affecting the pesticide deposition pattern on the crops and at the same time giving high pesticide waste due its enormous all direction drifts (He et al., 2017; Wang et al., 2017; Zhang et al., 2017 ).

A few researchers have analysed downwash airflow patterns due to the important role of downwash airflow in defining the distribution of droplets on crop canopy. Based on previous studies, the downwash airflow of a multi-copter was analyzed using computational and experimental studies. Computational Fluids Dynamics (CFD) has become a robust tool in agriculture. A research by Yang et al. (2018) has established the efficient threedimensional downwash numerical model based on compressible Reynolds-averaged NavierStokes (RANS) equations with the RNG k- $\varepsilon$ turbulence model of SLK-5 UAV, while hovering at $3 \mathrm{~kg}$ load condition. Zheng et al. (2018) also simulated the downwash field of six-rotors UAV at varying heights.

Experimental studies were also conducted to determine the downwash airflow. Although the development of the testing facility is considered limited and expensive, it is found to be the most accurate method in any fields. Cong et al. (2018) designed wind speed detection equipment using a pitot tube speed sensor based on a wind pressure signal to obtain better UAV wind parameters near the ground, which effectively detect the rotor wind speed data of the UAV and has a significant advantage of reducing interference. Chen et al. (2017) used the Wind Speed Sensor Network measurement system (WSSN) that used the impeller type of wind speed sensor that was arranged in one line and perpendicular to the flight path. Wu et al. (2019) determined the downwash airflow based on the strain effect principle. A total of 27 strain gauges were arranged in three levels under the hovering UAV at a location of $2.6 \mathrm{~m}$ above the ground and a blade rotation of $2500 \pm 10$ revolutions per minute (RPM). Feng et al. (2018) has also designed a facility with built-in blades and measured the downwash at hovering state with a blade speed of 2500 RPM using anemometers.

From the information provided by the experimental studies mentioned above, the concern is whether the downwash pressure profile and spray deposition of droplets obtained are presenting the behavior of the UAV during the spraying operation. It needs the understanding that the downwash flow field pattern is dynamically changed as the payload and the flight speed changes (due to the changes in the rotation of the blade). It is also worth noting that the downwash flow field also cannot be common standard to all spraying UAV due to their unique configuration (Teske et al., 2018). Therefore, this research is aimed to design and develop an indoor testing facility that imitates the UAV during spraying and at the same time, able to measure the downwash of the UAV and the deposition of droplets sprayed. By having this facility, the correlation between the downwash flow profile and deposition of droplets could be analyzed and this result may lead to determining the optimum spraying operating procedure for the UAV. 


\section{Design of Indoor UAV Testing Facility}

\subsection{Description}

Indoor UAV testing facility was designed primarily: (i) to evaluate the downwash airflow profile of the UAV using pressure transducers; and (ii) to quantify the spraying deposition using water-sensitive papers (spray width, droplet size $(\mu \mathrm{m})$, number of droplets per area and spray deposit volume $\left(\mu 1 / \mathrm{cm}^{2}\right)$ (Figure 1). The facility was located indoor to fully control the traveling operation of the tested UAV and overcome the environmental disturbances that may affect UAV spray deposition during operation. The overall length and height of the testing facility were approximately $23 \mathrm{~m}$ and $4.5 \mathrm{~m}$, respectively. The schematic diagram of the facility is as shown in Figure 1.

The testing facility has two main sections. The first section consists of a rail support structure and its driving unit (Figure 2(a) and 2(b)). The railing beam and its two-end column supports were built from a $305 \mathrm{~mm} \times 102 \mathrm{~mm} \times 33 \mathrm{~kg} / \mathrm{m}$ mild steel I beam. Attached to the beam is the moving carriage that was used to carry the tested UAV with a maximum weight limit of $100 \mathrm{~kg}$. This moving carriage could be adjusted at three levels of height from the ground: namely $1.5 \mathrm{~m}, 2.5 \mathrm{~m}$, and $3.5 \mathrm{~m}$ (Figure 2(c) and 2(d)). The forward speed of the moving carriage can be regulated up to a maximum of $10 \mathrm{~m} / \mathrm{s}$. This could be done by setting the required speed at the control console of the main driving unit. The height and speed of the carriage shall be set accordingly prior to the evaluation test. A mounting frame structure was built for securing the UAV to the moving carriage on the rail support structure (Figure 2(e) and (f)).

The second section is a sampling platform structure with total sampling area of $6 \mathrm{~m}$ $\mathrm{x} 6 \mathrm{~m}$ and its adjustable height chain level units at the sides. This entire sampling area can be manual set from the two height chain level units up to a maximum height of $3 \mathrm{~m}$ at $500 \mathrm{~m}$ intervals (Figure 2 (a) and $2(\mathrm{~g})$ ). This sampling area has a total of 49 measurement point fixtures that can be manually set to form a $0.5 \mathrm{~m} \times 0.5 \mathrm{~m}$ or $1 \mathrm{~m} \times 1 \mathrm{~m}$ grid coordinates in accordance to the required spray boom size of the tested UAV. Depending on the mode of conducted test, a pressure sensor or a water-sensitive paper was located at each sampling point on the grid coordinate of the sampling platform structure (Figure 2(h)).

The complete testing facility was equipped with the relevant sensor types to measure and record: (i) ambient air temperature, humidity and atmospheric pressure; (ii) spray downwash pressure at the respective 49 pressure transducer measurement points within the sampling area; (iii) the traveling speed of moving carriage with the test UAV using inductive proximity sensors which were located at fixed distance intervals on the railing beam. All these sensors were interfaced to a dedicated data acquisition system that was specially designed and developed for this test facility. 


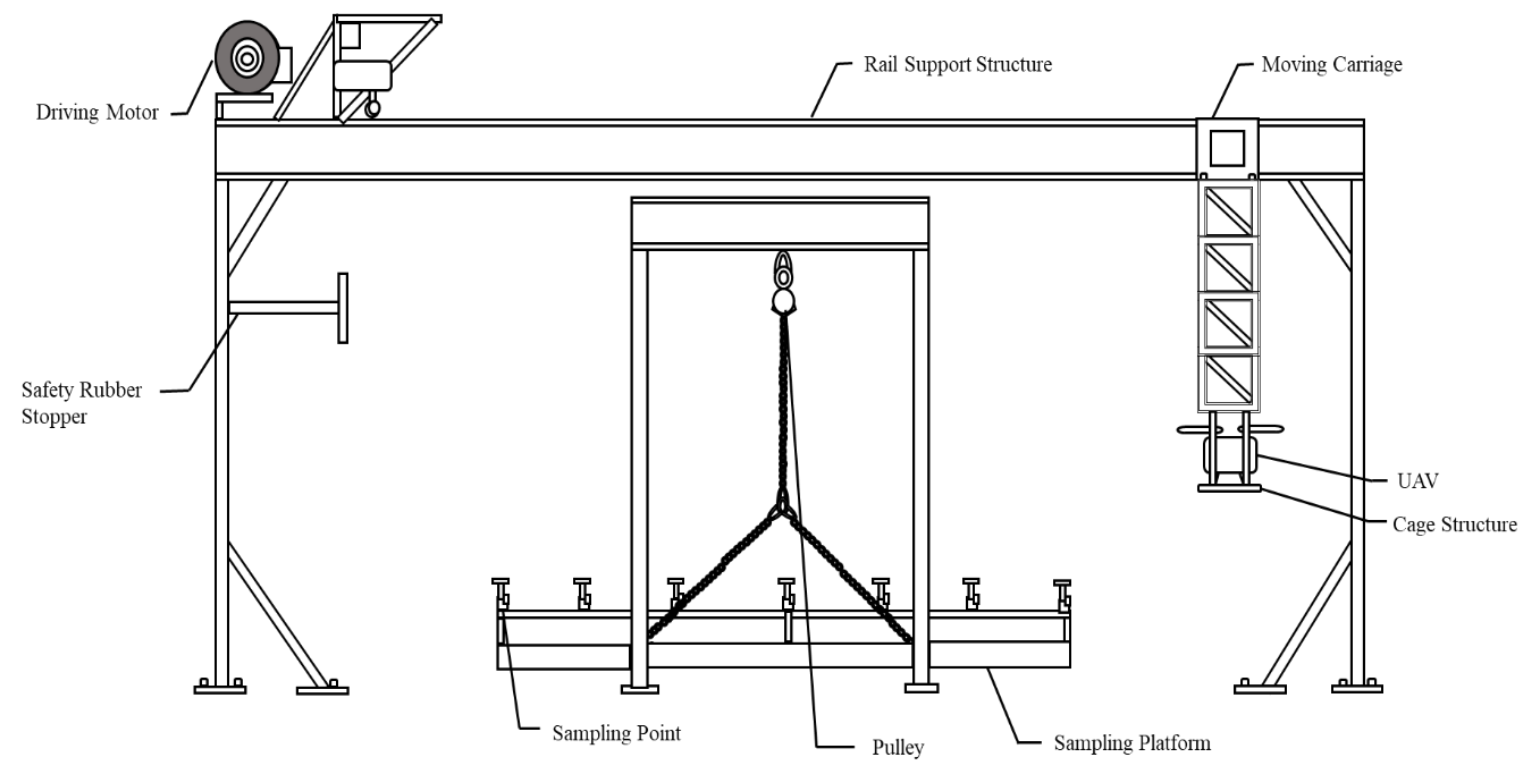

Figure 1. Schematic diagram of UAV testing facility.

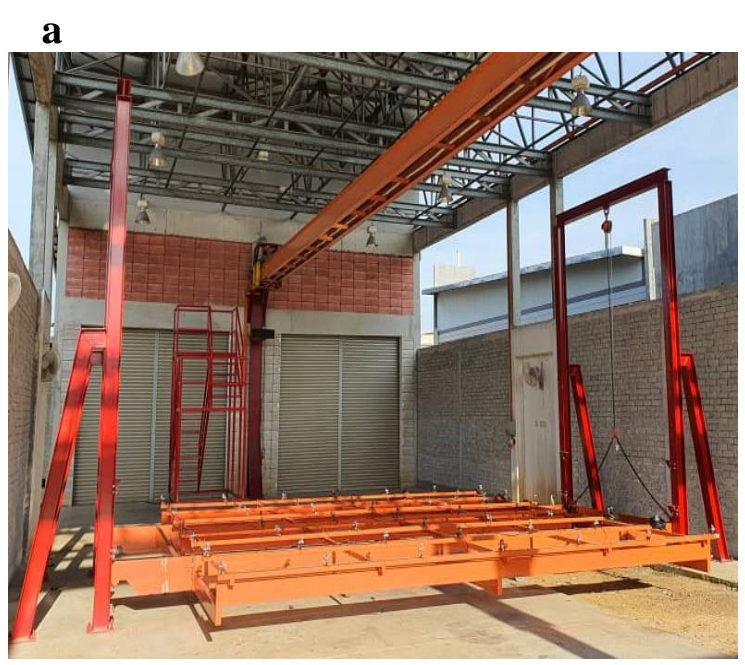

b

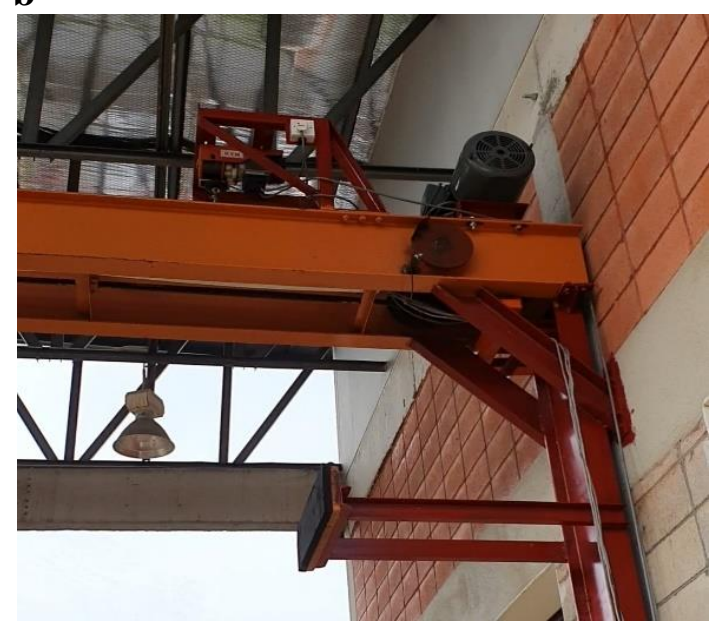

d

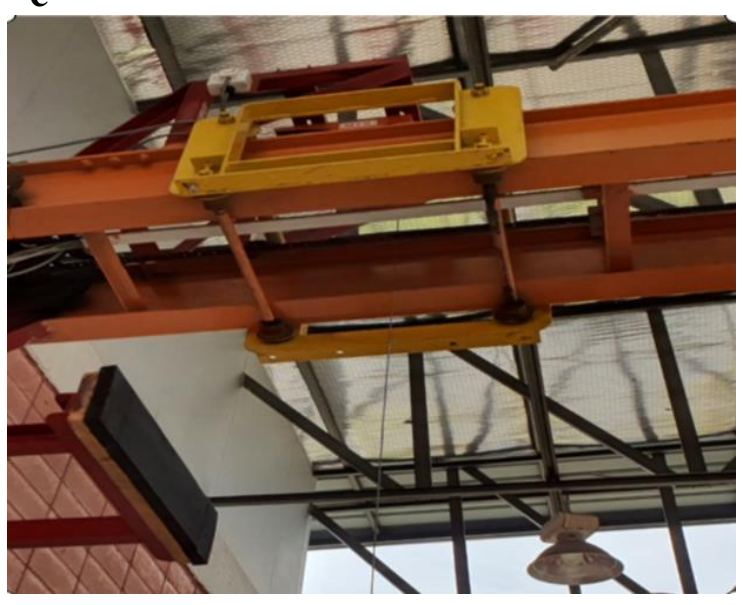

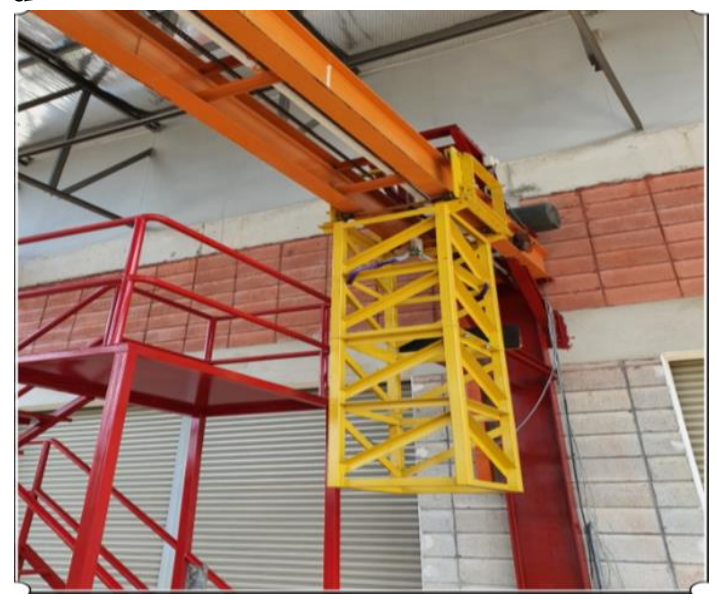


e
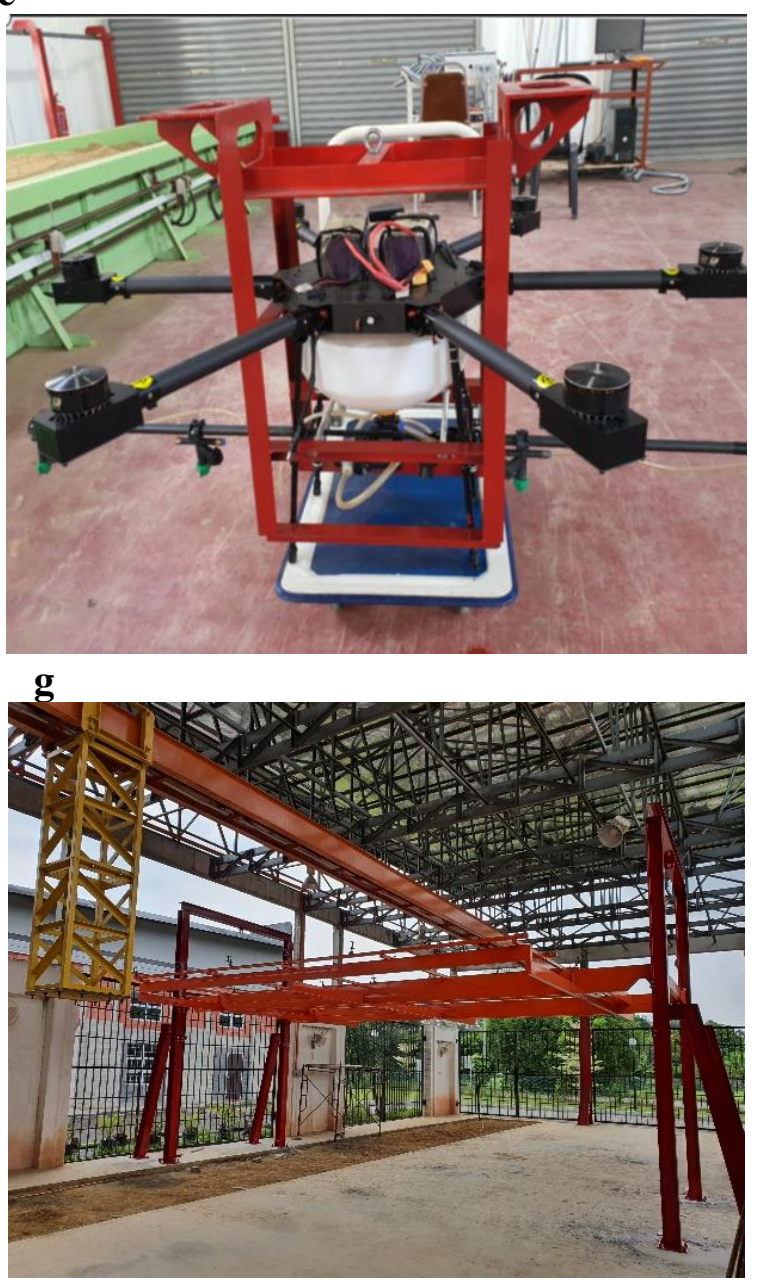

f

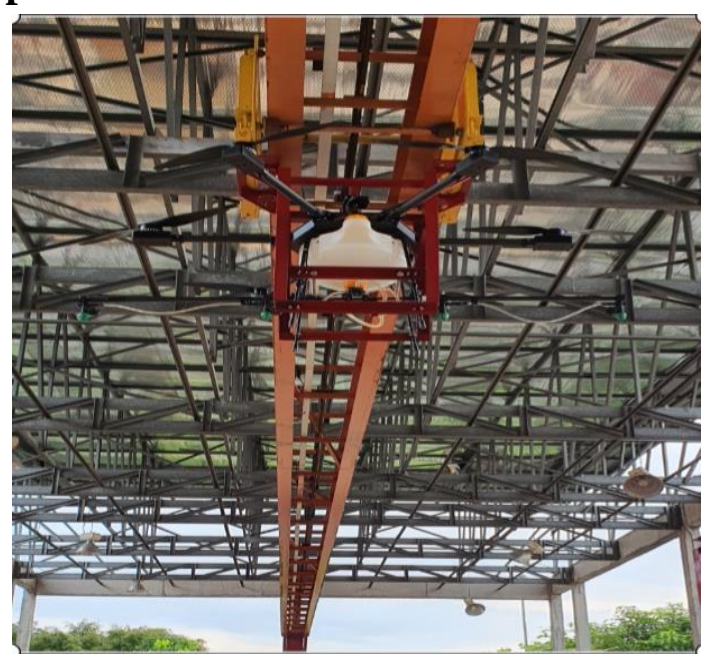

h

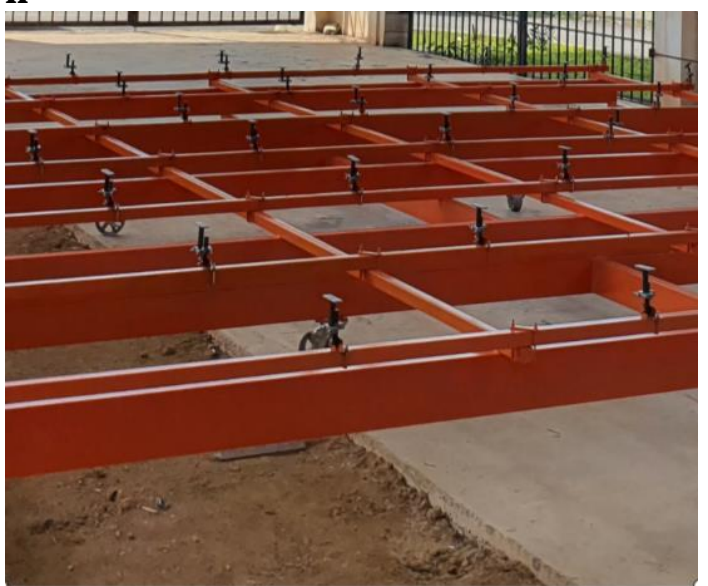

Figure 2. UAV testing facility main components: (a) rail support structure and sampling platform; (b) main driving unit; (c) moving carriage at the highest level; (d) moving carriage at the lowest level; (e) mounting frame structure for UAV; (f) UAV on the moving carriage at $3.5 \mathrm{~m}$ from the ground; (g) sampling platform at the highest level ( $3 \mathrm{~m}$ from the ground); (h) close-up of sampling points at grid of $1 \mathrm{~m} \times 1 \mathrm{~m}$.

\subsection{Operating Procedure}

A standard operating procedure has been formulated to operate this UAV testing facility in order to facilitate for a consistent reliable and repeatable test run. The involved procedure to set up the test UAV on the rail structure and the sampling platform have been summarized in the flowchart shown in Figure 3 (a) and (b). Each of the procedure is further discussed in the respective section below. 


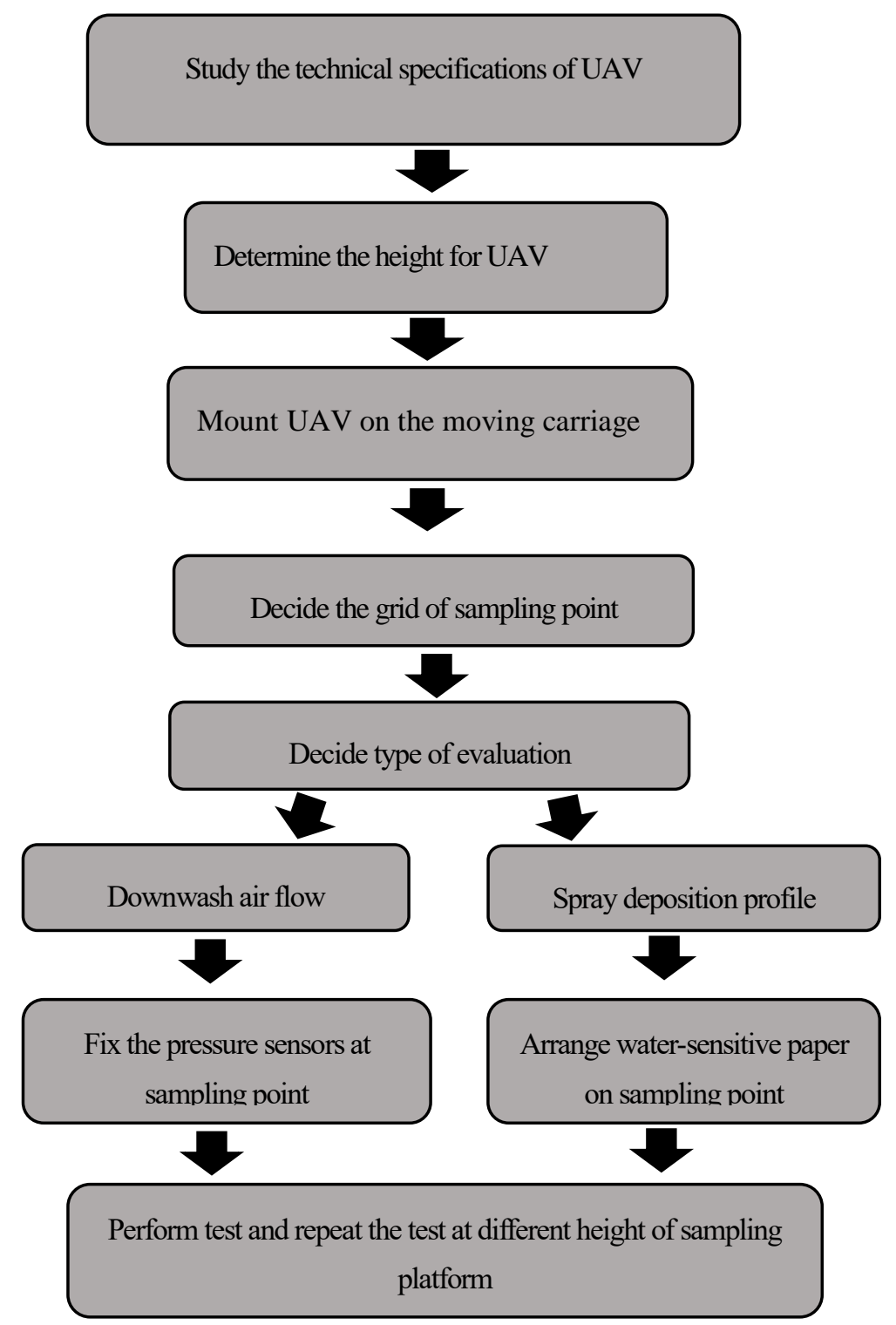

Figure 3(a). Operating procedure for UAV set-up on rail structure. 


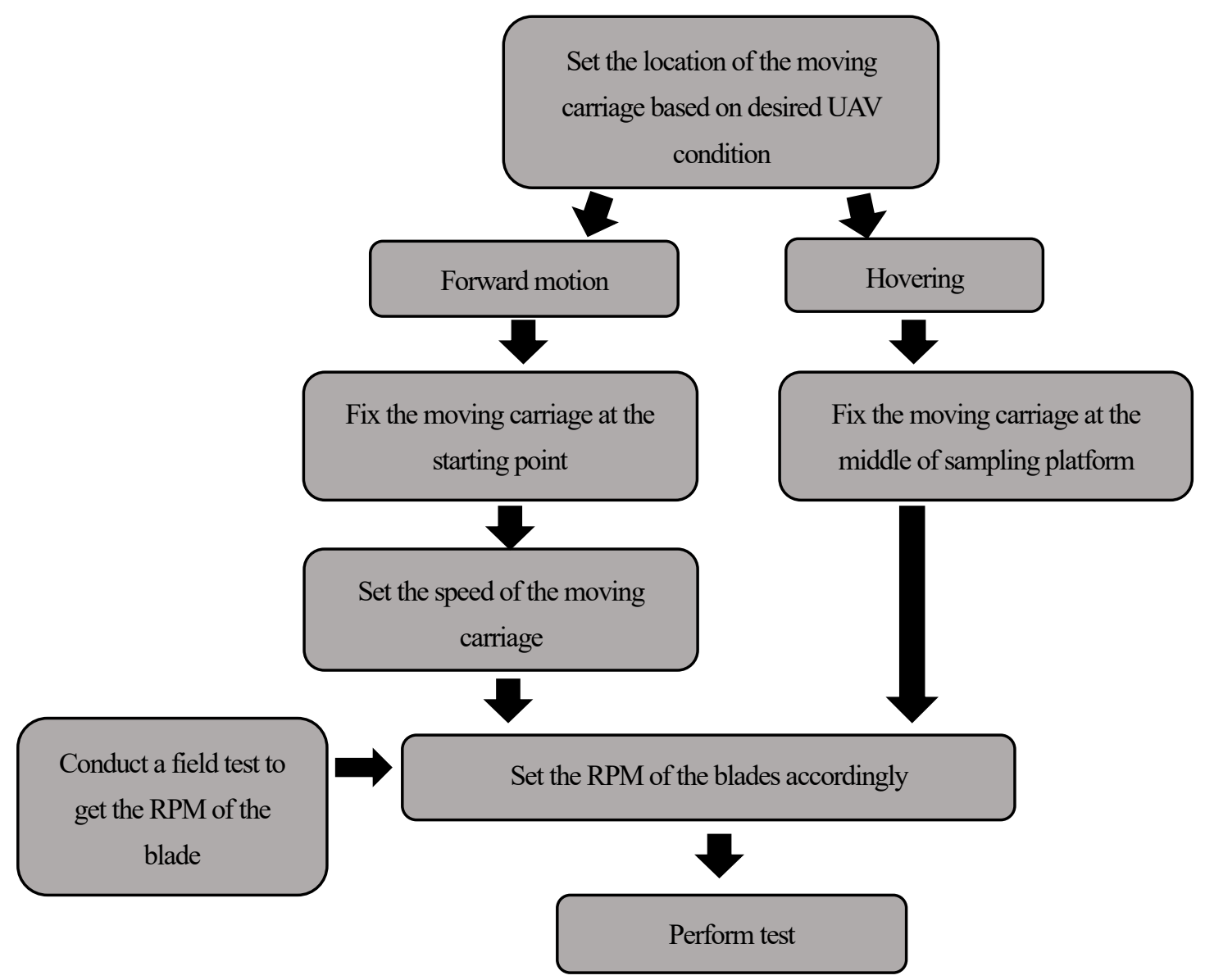

Figure 3(b). Operating procedure for sampling platform set-up.

\subsubsection{Selection of $U A V$}

The UAV that is commonly used for aerial chemical spraying in wetland rice cultivation in Malaysia was selected for this research (Figure 4). The technical specifications of the UAV are as shown in Table 1.

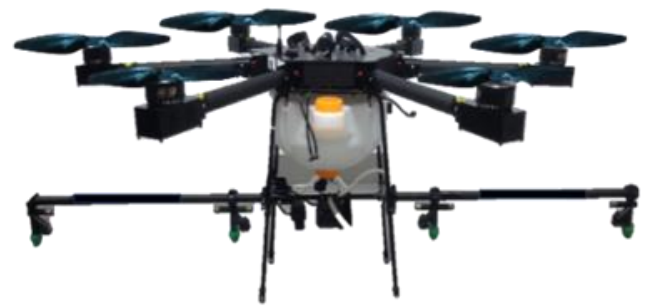

Figure 4. Picture of actual UAV. 
Table 1. Technical specifications of UAV.

\begin{tabular}{|c|c|c|c|c|c|c|c|}
\hline Model & $\begin{array}{c}\text { Year } \\
\text { manufactured }\end{array}$ & $\begin{array}{l}\text { Number of } \\
\text { propellers }\end{array}$ & $\begin{array}{c}\text { Type of } \\
\text { propeller }\end{array}$ & $\begin{array}{c}\text { Type of } \\
\text { brushless } \\
\text { motor }\end{array}$ & $\begin{array}{l}\text { Power } \\
\text { Source }\end{array}$ & $\begin{array}{c}\text { Max. } \\
\text { payload }\end{array}$ & $\begin{array}{c}\text { Gross } \\
\text { UAV } \\
\text { weight }\end{array}$ \\
\hline $\begin{array}{c}\text { Advansia } \\
\text { A1 }\end{array}$ & 2015 & $\begin{array}{c}6 \\
\text { (Hexa } \\
\text { UAV) }\end{array}$ & $\begin{array}{l}\text { T2255 - } \\
\text { Carbon } \\
\text { fibre } \\
\text { straight }\end{array}$ & $\begin{array}{l}\text { JMR } 6215 \\
-\mathrm{KV} 170\end{array}$ & $\begin{array}{c}\text { Poly } \\
\text { Lithium } \\
\text { Battery } \\
\text { x } 2 \\
(16000 \\
\text { mAh })\end{array}$ & $10 \mathrm{~L}$ & $\begin{array}{c}25 \mathrm{~kg} \\
\text { (maximum } \\
\text { with } \\
\text { payload) } \\
15 \mathrm{~kg} \\
\text { (without } \\
\text { payload) }\end{array}$ \\
\hline
\end{tabular}

\subsubsection{Setting the height, speed and location of moving carriage}

The height and speed of the moving carriage of the rail support structure need to be set before executing the spraying evaluation on the tested UAV. Depending on the intended height and speed parameters, the chosen height of the moving carriage should be either 1.5 $\mathrm{m}, 2.5 \mathrm{~m}$, and $3.5 \mathrm{~m}$ from the ground, while moving at a maximum speed of $10 \mathrm{~m} / \mathrm{s}$. The moving carriage had to be located in the middle of the sampling area for the spraying evaluation under hovering condition. For evaluation of spraying under moving condition, the moving carriage with the mounted UAV was set to move from the starting point location until the end point of the railing beam.

\subsubsection{Setting the revolution per minute (RPM) of the blades}

In order to obtain the downwash data of the UAV using the facility, the numbers of blade's turns in one minute or known as revolution per minute (RPM) must be set similar to the RPM of the blades during spraying. A field test was carried out beforehand to obtain the RPM data of each blade of the UAV. In this field test, the RPM of each blade on the UAV was recorded, while flying the UAV at the different pay load and flying speed. After the field test, these recorded RPMs would be accessed from the UAV flight controller console using the interface software. These RPM data would be used as a reference when setting up the RPM of the individual blades during the evaluation test using the UAV testing facility.

\subsubsection{Deciding the area of the sampling point}

The sampling point area had to be determined according to the spray boom size of the tested UAV. The sampling point available on the sampling platform structure could be fixed either at the grid of $0.5 \mathrm{~m} \times 0.5 \mathrm{~m}$ or $1 \mathrm{~m} \times 1 \mathrm{~m}$ sampling points. 


\subsubsection{Deciding the type of evaluation}

There are two types of evaluation tests that can be carried out using this testing facility. The first type was to evaluate the downwash pressure of the UAV blades with the pitot tube sensors located at the grid measurement points. The second type was to evaluate the droplet deposition of the UAV sprayer boom with water-sensitive paper located at the grid measurement points. All the available pressure sensors on the sampling platform must be replaced with the water-sensitive papers if the conducted test was set to continue after the evaluation of the downwash pressure.

\subsubsection{Acquiring downwash flow field}

The downwash flow field could be recorded while the UAV was under hovering and moving modes. For hovering, the UAV at the specific height and the RPM (refer to sections 2.2.2 and 2.2.3) was set to be located in the middle of the sampling area. Pressure sensors would be set to collect the readings of the downwash pressure. In order to obtain a complete $3 \mathrm{D}$ profile spectrum of pressure readings, the test was repeated at different height of sampling platform.

In order to acquire the downwash flow field while UAV was moving, the RPM of the UAV blades as specified in section 2.2.3 had to be set to the desired moving speed and payload. In addition, the height and speed of the moving carriage of the testing facility had to be set accordingly (section 2.2.2). As the moving carriage with the tested UAV moves along the railing beam, the pressure sensors located on the sampling platform structure would capture the downwash pressure readings and record the capture readings on the data acquisition system at the same time. The same test had to be repeated in order to get the 3D downwash pressure profile at different levels of height by increasing or lowering the sampling platform structure of the testing facility. All pressure data recorded would be analyzed using MATLAB software (The MathWorks, Inc).

\subsubsection{Verifying the droplet deposition}

To measure the distribution of droplet deposition, water-sensitive papers were fixed at all available points on the sampling platform. As explained in sections 2.2.2 and 2.2.3, the application parameters such as blades RPM, height and speed of the carriage were to be set accordingly. The UAV spraying tank should be earlier filled with the spray chemicals and the spray system had to be set to run at $10 \mathrm{sec}$ under a still position before the start of the test to ensure that the flow was stable. All water-sensitive papers should be collected immediately upon the completion of the UAV test run. Each of the collected water-sensitive papers need 
to be scanned using a portable scanner and then analyzed using the droplet deposition imaging system 'DepositScan' by USDA developed by Zhu et al. (2011).

The information that could be gathered from this test includes swath width and droplet distribution profile (droplet spectrum in $\mu \mathrm{m}$ ) such as the number of droplet per area and concentration of deposition per area $\left(\mu \mathrm{L} / \mathrm{cm}^{2}\right)$. The deposition result could then be matched to the downwash data and would be used to determine the optimum application parameters for the UAV in the later actual field spraying operation.

\section{Preparing Report}

The test report to be prepared would include detail documentation on the technical specification of the test drone and related picture or technical drawing of the test drone, spraying application parameters (i.e. release height and travel speed), spray system technical specifications (i.e. spray pressure, flow rate, application rate, nozzle type, nozzle distance, and the number of nozzle), spraying material specifications (i.e. temperature of spraying materials and its physical properties), ambient conditions (i.e. air temperature, relative humidity and atmospheric pressure) and the details results from the evaluation.

\section{Expected Result}

With the establishment of this Indoor UAV testing facility, the downwash airflow and spraying performance of any agricultural UAV could be determined to allow proper recommendations on the flying requirements of the UAV in order to achieve an efficient agricultural spraying operation.

The testing facility is expected to be a platform for the UAV industry to improve the current UAV or to design a new UAV with the best combinations of configurations and spraying system to maximize spraying efficiency. The testing facility could also allow for a detailed study of the development and evaluation of the new chemical spray formulations for aerial spraying using UAV.

\section{Conclusion}

In this paper, an indoor test facility was designed and developed to evaluate agricultural UAVs in hovering and forward motion modes for their downwash airflow and spraying performance. The rail support structure with the carriage was designed to carry the UAV and the sampling platform was constructed under the rail structure to collect data on the downwash pressure and the spray distribution of the test UAV. A standard testing procedure was formulated to provide the performance evaluations to undergo under the same standard protocols. 
The rig could also be used to carry out a detailed study on the development and evaluation of new chemical spray formulations for aerial spraying using UAV and as a testing platform for the UAV industry.

Author Contributions: writing — original draft preparation, S.A. Ismail.; writing-review and editing, S.A. Ismail, A.Yahya, A.S. Mat Su, N. Asib, and A. Mohd Mustafah.

Funding: This work was funded from the Matching-Grant Putra with grant number 9300461.

Acknowledgments: The researchers would like to thank Poladrone Sdn. Bhd. and Advansia Sdn.Bhd. for the UAV and its accessories, advices, and assistance.

Conflicts of Interest: The authors declare no conflict of interest.

\section{References}

Chen, S. D., Lan, Y. B., Li, J. Y., et al. (2017). Effect of wind field below unmanned helicopter on droplet deposition distribution of aerial spraying. International Journal of Agriculture \& Biological Engineering. 10(3), 67-77.

Cong, H., Jiyu, L., Yubin, L., et al., (2018). Design and experiment of a wind speed detection equipment with wind pressure conversion near ground. Journal of South China Agricultural University, 39(1), 105-111 ref.21.

Faiçal, B.S., Pessin, G., Ueyama, J., et al., (2017). An adaptive approach for uav-based pesticide spraying in dynamic environments. Computers and Electronics in Agriculture, 138, 210-223.

Feng, T., Qi, L., Chang-liang, L., et al., (2018). Measurement of downwash velocity generated by rotors of agriculture drones. INMATEH Agricultural Engineering, 55(2), 141-150.

Giles, D. K., \& Billing, R. (2014). Unmanned aerial platforms for spraying: Deployment and performance. Aspects of Applied Biology, 12, 63-69.

He, X. K., Bonds, J., Herbst, A., et al., (2017). Recent development of unmanned aerial vehicle foor plant protection in East Asia. International Journal of Agricultural and Biological Engineering, 10(3),18-30.

Hofman, V., \& Solseng, E., (2017). Reducing spray drift. NDSU Extension Service. Retrieved from https://www.ag.ndsu.edu/publications/crops/reducing-spray-drift/ae1210.pdf

Huang, Y., Hoffmann, W.C., Lan, Y., et al. (2009). Development of a spray system for an unmanned aerial vehicle platform. Applied Engineering in Agriculture, 25(6),803-809.

Huang, Y., Thomson S. J., Hoffmann, W.C., et al., (2013). Development and prospect of unmanned aerial vehicle technologies for agricultural production management. International Journal of Agricultural and Biological Engineering, 6(3),1-10.

Meivel, S., Maguteeswaran, R., Gandhiraj, N., et al., (2016). Quadcopter uav based fertilizer and pesticide spraying system. International Academic Research Journal of Engineering Sciences, 1(1), 8-12.

Morley, C. G., Broadley, J., Hartley, R., et al. (2017). The potential of using unmanned aerial vehicles (UAVs) for precision pest control of possums (Trichosurus vulpecula). Rethinking Ecology, 2, 27-39.

Puig, E., Mcfadyen, A., \& Gonzalez, F. (2018). Advances in unmanned aerial systems and payload technologies for precision agriculture. In Chen G, Advances in Agricultural Machinery and Technologies (pp. 133-155). Boca Raton: CRC Press. 
Pscheidt J. W. (2012). Improving spray efficiency. Pest management handbook. Retrieved from https://pnwhandbooks.org/plantdisease/pesticide-articles/improving-spray-efficiency.

Qin, W. C., Qiu, B. J., Xue, X. Y., et al. (2016). Droplet deposition and control effect of insecticides sprayed with an unmanned aerial vehicle against plant hoppers. Crop Protection, 85, 79-88.

Teske M. E., Wachspress D. A., \& Thistle H. W. (2018). Prediction of aerial spray release from UASs. Transaction of the ASABE, 61(3), 909-918.

Wang, S. L., Song, J. L., He, X. K., et al. (2017). Performances evaluation of four typical unmanned aerial vehicles used for pesticide application in China. International Journal of Agriculture \& Biological Engineering, 10(4), 22-31.

Wu, Y., Qi, L., Zhang, H., et al., (2019). Design of UAV downwash airflow field detection system based on strain effect principle. Sensors, 19(1), 1-18. doi:10.3390/s19112630.

Yang, F. B., Xue, X. Y., Zhang, L., et al. (2017). Numerical simulation and experimental verification on downwash air flow of six-rotor agricultural unmanned aerial vehicle in hover. International Journal of Agricultural and Biological Engineering, 10(4), 41-53.

Yang, F. B., Xue, X., Cai, C., et al. (2018). Numerical simulation and analysis on spray drift movement of multirotor plant protection unmanned aerial vehicle. Energies, 11(9), 1-20. doi:10.3390/en11092399.

Zhang, P., Deng, L., Lyu, Q., et al. (2016). Effect of citrus tree shape and spraying height of small unmanned aerial vehicle on droplet distribution. International Journal of Agricultural and Biological Engineering, 9 (4), 45-51.

Zhang, S. C., Xue, X. Y., Sun, Z., et al. (2017). Downwash distribution of single rotor unmanned agricultural helicopter on hovering state. International Journal of Agricultural and Biological Engineering, 10(5), 14-24.

Zheng, Y., Yang, S., Liu, X., et al. (2018). The computational fluid dynamic modelling of downwash flow field for a sixrotor UAV. Frontiers of Agricultural Science and Engineering, 5(2), 159-167. doi: https://doi.org/10.15302/JFASE-2018216.

Zhu, H., Salyani, M., Fox, R. D. et al. (2011). A portable scanning system for evaluation of spray deposit distribution. Computers and Electronics in Agriculture, 76, 38-43. https://doi.org/10.1016/j.compag.2011.01.003.

Copyright $\odot 2020$ by Ismail SA et al. and HH Publisher. This work is licensed under the Creative Commons Attribution-NonCommercial 4.0 International Lisence (CC-BY-NC4.0) 
